Ramón Fernández, Francisca.

Profesora titular de Derecho civil, Universitat Politècnica de València, Departamento de Urbanismo.

\title{
La delimitación del entorno de protección y su influencia en la conservación de los Bienes de Interés Cultural Inmaterial.
}

\author{
TIPO DE TRABAJO \\ Comunicación. \\ PALABRAS CLAVE \\ Patrimonio cultural; entorno de protección; conservación; legislación; bienes de interés cultural inmaterial.
}

KEY WORDS

Cultural heritage, environment protective; conservation; legislation; intangible goods of cultural interest.

\section{RESUMEN}

La Ley 4/1998, de 11 de junio, del Patrimonio Cultural de la Comunidad Valenciana, modificada por Ley 7/2004, de 19 de octubre, y por Ley 5/2007 contempla la protección de los bienes de interés cultural (BIC) de los inmateriales. Se refiere a las actividades, creaciones, conocimientos, prácticas, usos y técnicas representativos de la cultura tradicional valenciana, así como las manifestaciones que sean expresión de las tradiciones musicales, artísticas o de ocio. En la declaración de un BIC debe establecerse el entorno afectado. Es por ello, que en el presente trabajo nos proponemos reflexionar sobre la importancia del entorno de protección como medida de conservación de los bienes protegidos, mediante el análisis de diversos supuestos prácticos en los que resulta especialmente significado, así como las consecuencias de dicha delimitación.

\section{ABSTRACT}

The Law 4/1998, of June 11, of the Cultural Heritage of the Valencian Community, modified by Law 7/2004, of October 19, and for Law 5/2007 he contemplates the protection of the goods of cultural interest (BIC) of the immaterial ones. It refers to the activities representative, creations, knowledge, practices, uses and technologies of the traditional Valencian culture, as well as the manifestations that are an expression of the musical, artistic traditions or of leisure. In the declaration of a BIC the affected environment must be established. It is for it, which in the present work we propose to think on the importance of the protection environment as measure of conservation of the protected goods, by means of the analysis of diverse practical suppositions in which it turns out to be specially important, as well as the consequences of the above mentioned delimiting.

\section{INTRODUCCIÓN}

La máxima protección que concede la legislación de patrimonio cultural valenciano, representada por la Ley 4/1998, de 11 de junio, del Patrimonio Cultural de la Comunidad Valenciana (BOE núm. 174, de 22 de julio de 1998), modificada por Ley 7/2004, de 19 de octubre (BOE núm. 279, de 19 de noviembre de 2004), y por Ley 5/2007, de 9 de febrero (BOE núm. 71, de 23 de marzo de 2007), a los bienes al protegerlos como bienes de interés cultural (BIC), en especial a los inmateriales, hace que sea especialmente importante la delimitación del entorno de protección de dicho bien, para determinar hasta dónde se extiende la indicada protección.

En el presente trabajo vamos a analizar algunos supuestos de bienes inmateriales protegidos y la delimitación de su entorno de protección como medio de incrementar su conservación, por lo que vamos a prestar especial atención al ámbito temporal y al ámbito espacial de cada uno de los bienes. 


\section{LA DELIMITACIÓN DEL ENTORNO DE PROTECCIÓN Y SU INFLUENCIA EN LA CONSERVACIÓN DE LOS BIENES DE INTERÉS CULTURAL INMATERIAL}

Según establece la legislación de patrimonio cultural valenciano, mencionada anteriormente, pueden ser declarados de interés cultural no sólo los bienes inmuebles, y muebles, sino los denominados bienes inmateriales o intangibles.

Se trata de las actividades, creaciones, conocimientos, prácticas, usos y técnicas que constituyen las manifestaciones más representativas y valiosas de la cultura y los modos de vida tradicionales de los valencianos.

Igualmente podrán ser declarados bienes de interés cultural los bienes inmateriales que sean expresiones de las tradiciones del pueblo valenciano en sus manifestaciones musicales, artísticas, gastronómicas o de ocio, y en especial aquellas que han sido objeto de transmisión oral, y las que mantienen y potencian el uso del valenciano.

En la declaración de un BIC se establecerá la delimitación geográfica y el entorno afectado por la declaración en razón de la adecuada protección del bien y de su relación con el área territorial a la que pertenece, incluyéndose el subsuelo, si procede, en el caso de los bienes inmuebles (Ramón, 2012).

El art. 45 de la Ley 4/1998, establece la declaración y el régimen de protección de los bienes inmateriales de interés cultural. De este modo, el Decreto establecerá las medidas de protección y fomento de la manifestación cultural objeto de la declaración que mejor garanticen la conservación. Se ordenará el estudio y la documentación con criterios científicos de la actividad o conocimiento de que se trate, incorporando los testimonios disponibles de éstos a soportes materiales que garanticen su pervivencia (Ramón, 2012).

También se contempla la posibilidad de incluir en el Inventario General del Patrimonio Cultural Valenciano, con la calificación de Bienes Inmateriales de Relevancia Local (BIRL) y teniendo en cuenta lo indicado en el Decreto 62/2011, de 20 de mayo, del Consell, por el que se regula el procedimiento de declaración y el régimen de protección de los bienes de relevancia local (DOCV núm. 6529 , de 26 de mayo de 2011), teniendo en cuenta las consideraciones mencionada sobre los bienes inmateriales (creaciones, conocimientos, formas tradicionales valencianas, entre otros).

El procedimiento para su inclusión en el Inventario, en los casos en que no fueran estos bienes objeto de protección como BIC, se hará mediante la resolución de la Conselleria competente, previa la tramitación del procedimiento, de oficio o a instancia de parte. Esta incoación, que si se deniega se tendrá que motivar, se notificará a las entidades públicas o privadas directamente relacionadas con la práctica o conocimiento objeto de la misma.

La resolución deberá dictarse en un plazo máximo de un año desde la solicitud o incoación y dará lugar a la inscripción del bien en la sección 5a. del inventario.

La resolución que determine la inclusión de un bien inmaterial en el inventario establecerá las medidas para su preservación y difusión de su conocimiento, según lo que indica el art. 45 de la Ley 4/1998.

Vamos, pues, a ver algunos ejemplos de delimitación del espacio espacial y temporal, así como del entorno de protección en la declaración como $\mathrm{BICl}$ de los bienes del patrimonio cultural valenciano (Ramón, 2014).

1. Les Fogueres de Sant Joan de Alicante declaradas como BIC por Decreto 222/2014, de 19 de diciembre (DOCV núm. 7428 , de 22 de diciembre de 204), indican respecto al espacio protegido, que la fiesta se desarrolla en la ciudad de Alicante, ligadas al vecindario, y que se planta el monumento en la calle o plaza, extendiéndose a las inmediaciones y calles adyacentes. En cuanto al ámbito temporal, se circunscribe a las fechas del 20 al 24 de junio, precedidas por los actos preliminares que organiza la Federación de Les Fogueres de Sant Joan.

2. El ritual del Pa Beneit de Torremanzanas declarado como BIC por Decreto $153 / 2014$, de 26 de septiembre (DOCV núm. 7370 , de 29 de septiembre de 2014), establece el ámbito temporal a la población de Torremanzanas, teniendo como escenario el templo parroquial de Santa Ana, que es el punto de convergencia del desfile que arranca desde el portal de las casas de los llumeners. El ámbito temporal es el 9 de mayo, día de la festividad de san Gregorio Ostiense, patrón de la ciudad de Torremanzanas.

3. Los toques manuales de campanas en la Iglesia Parroquial de la Asunción de Ntra. Sra. de Albaida, en el campanar de la Vila de Castellón de la Plana, en la Santa Iglesia Catedral de Santa María de la Asunción de Segorbe y en la Santa Iglesia Catedral Basílica Metropolitana de Santa María de Valencia, declarados como BIC por Decreto 111/2013, de 1 de agosto, del Consell (DOCV núm. 7082, de 05 de agosto de 2013), el ámbito espacial se establece al denominado paisaje sonoro de las ciudades de Albaida, Castellón de la 
Plana, Segorbe y Valencia, en torno a los campanarios, entendiéndose como aquél territorio hasta donde alcanza el sonido de las campanas y los toques manuales o tradicionales. El ámbito temporal son los ciclos anuales ordinarios, así como las excepciones que contemplan las consuetas, como son los toques festivos extraordinarios o los toques de difuntos (Ramón, 2014).

4. Fallas de Valencia declaradas como BIC por Decreto 44/2012, de 9 de marzo, del Consell (DOCV núm. 6732 , de 12 de marzo de 2012), el ámbito temporal es la ciudad de Valencia, siendo una fiesta vecindaria que tiene como centro neurálgico la calle o plaza donde se planta la falla, y se extiende a las inmediaciones y calles adyacentes. El ámbito temporal es la denominada "semana fallera" abarcando los días del 14 al 19 de marzo, precedida de los actos preliminares que anuncian la fiesta.

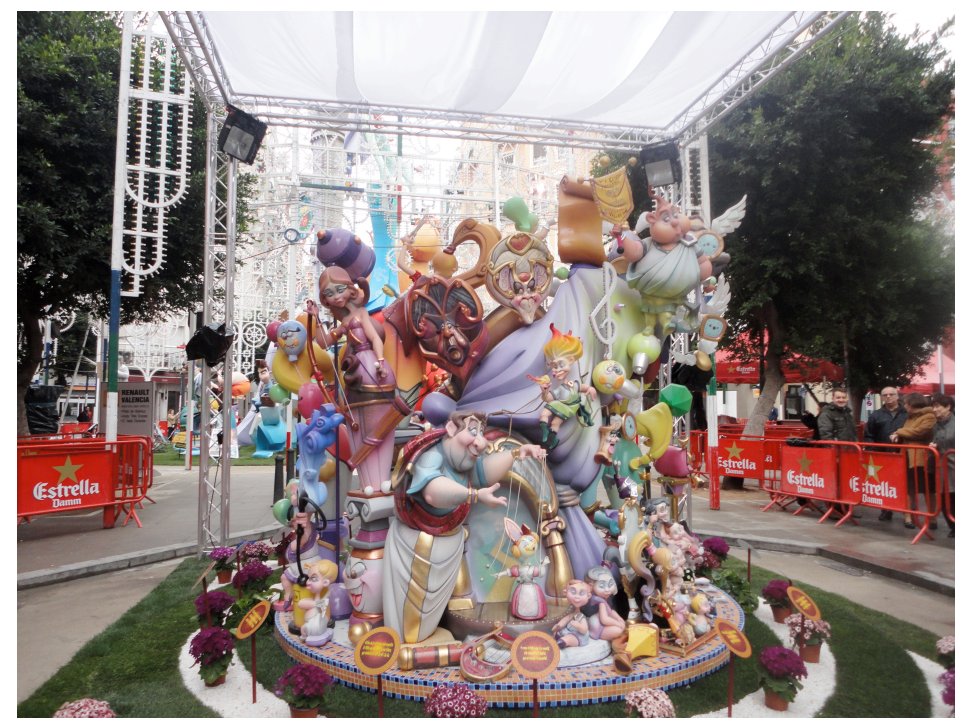

\section{llustración 1. Detalle de Falla infantil. Año 2015. (Elaboración propia)}

5. Las Tamboradas de Alzira y de la Rompida de la Hora de L'Alcora declaradas como BIC por Decreto 11/2012, de 13 de enero, del Consell (DOCV núm. 6692, de 16 de enero de 2012).

Por lo que se refiere a la Tamborada, el ámbito espacial es desde cada uno de los locales que se ubican en diferentes sectores urbanos desde donde salen las bandas de tambores para agruparse posteriormente en espacios comunes, como son la Plaza Mayor, la del Carbón ante el Ayuntamiento o en el Palacio de Deportes. También el desfile que se celebra por la tarde, con todas las bandas de tambores participantes, se inicia en una de las parroquias de la localidad, alternándose rotativamente para acabar en la Plaza Mayor.

El ámbito temporal de la Tamborada es en Cuaresma y Semana Santa. De esta forma, la Tamborada, Jornada de Exaltación del Tambor y el Bombo de la Ciudad de Alzira, debe buscar su ajuste en tiempo de Cuaresma, donde comparte calendario con otras manifestaciones de la Semana Santa, tales como la Procesión Diocesana y la Tamborada Nacional, en las que participa también el tambor.

En cuanto a la Rompida de la Hora de L'Alcora, el ámbito espacial se desarrolla en el municipio de L'Alcora, en las calles de su casco antiguo. Comienza en la Plaza de España, y su recorrido posterior de los tambores por distintas calles del centro de la villa, finalizando en la Plaza de la Iglesia.

El ámbito temporal tiene lugar el Viernes Santos, festividad que no tiene fecha fija en el calendario, y que puede cambiar cada año. Tiene una duración de una hora, empezando a las 12.00 del mediodía, recorriendo las calles indicadas, y finalizando a las 13.00 horas.

6. La Fiesta de la Santantonada de Forcall declarada como BIC por Decreto 10/2012, de 5 de enero, del Consell (DOCV núm. 6688 , de 10 de enero de 2012), establece su ámbito temporal al mes de enero, durante el fin de semana más próximo a la festividad de san Antonio Abad, que se celebra el 17 de enero, desarrollándose durante tres días: viernes, sábado y domingo. El ámbito espacial son los diversos desfiles que transcurren por las principales calles del casco antiguo de Forcall, en el que se incluye la plaza, donde se monta la barraca.

7. La Cabalgata de los Reyes Magos de Alcoy declarada como BIC por Decreto 199/2011, de 23 de diciembre, del Consell (DOCV núm. 6678 , de 26 de diciembre de 2011), indica que el ámbito espacial y temporal se inicia con les pastoretes que se celebra la mañana del domingo o del día festivo anterior al 5 de enero, a las 12.00 horas desde el Partidor (zona alta de la calle de Sant Nicolau) y finaliza en 
la plaza de Espanya. El Bando Real se celebra la tarde del 4 de enero, iniciándose a las 18.30 horas con el Pregó del tio Piam y continuando sobre las 19.00 horas con el cortejo del Bando Real, por las calles de Alcoy.

La Cabalgata se celebra al atardecer del día 5 de enero, víspera de la fiesta de los Reyes Magos, cuyo itinerario transcurre a lo largo de más de dos kilómetros y medio de camino, a través de la ciudad de Alcoy.

8. La entrada de toros y caballos de Segorbe declarado como BIC por Decreto 6/2011, de 4 de febrero (DOCV núm. 6454 , de 07 de febrero de 2011), establece el ámbito espacial y temporal de la siguiente forma:

La longitud del recorrido de la entrada de toros en 450,20 metros desde el lugar de la torre de Bochí donde se coloca la puerta de la salida de los toros, hasta la denominada "tanca de Correos" entre la plaza de la Cueva Santa y la de San Pedro.

La superficie total del recorrido son de 5.709 metros cuadrados que comprenden la calle Argén, la calle Colón y la plaza de la Cueva Santa.

El perímetro del recorrido es de 943,61 m lineales. La anchura mínima en el trazado de 6,20 m. en la zona denominada del Estrecho, a la altura de la puerta principal de entrada al seminario, y la máxima en el trazado de $22,70 \mathrm{~m}$. en los Mesones, a la altura del Museo Municipal de Arqueología.

La duración de la entrada de toros y caballos oscila entre los 40-45 segundos, desde la salida de los toros desde la plaza de los Mesones hasta la puerta de entrada en la plaza de la Cueva Santa, siempre a las $14 \mathrm{~h}$.

9. Festa de la Mare de Déu de la Salut de Algemesí declarada BIC por Decreto 117/2010, de 27 de agosto (DOCV núm. 6345, de 01 de septiembre de 2010). El ámbito espacial queda constituido por el municipio de Algemesí, siempre en los alrededores de la parroquia de San Jaime y de la capilla de la "Troballa", con un recorrido diferente para cada una de las procesiones. Hay definidos tres itinerarios, el de la procesión de "les Promeses", la "processoneta del Matí" y la procesión de la "Volta General".

El ámbito temporal es la festividad que se celebra anualmente del 29 de agosto al 6 de septiembre, que es el novenario; el 7 de septiembre que es la víspera de "la Mare de Déu de la Salut", repique de la "Xirivia" y Procesión de "les Promeses". El 8 de septiembre es la Fiesta de "la Mare de Déu" y la "Processoneta del Mati" y procesión de la "Volta General".

10. La Solemnidad del Corpus Christi en la ciudad de Valenciana declarado BIC por Decreto 92/2010, de 28 de mayo, del Consell (DOCV núm. 6280, de 02 de junio de 2010). La definición del ámbito espacial y temporal queda constituído por la Cabalgata del Convite, en el que desfilan, acompañados de dulzaina y tamboril (les banderoles; els gegants; els nanos; el capellà de les Roques; la Moma; els cavallets o morets; la magrana; els arquets; els pastorets; els llauradors; els turcs; personajes de los Misteris; la degollà), las Rocas (la diablera; sant Miguel, la fe; sant Vicent Ferrer; la purissima; la valència; la fama; el patriarca; la santissima trinita; la virgen de los desamparados y el santo cáliz).

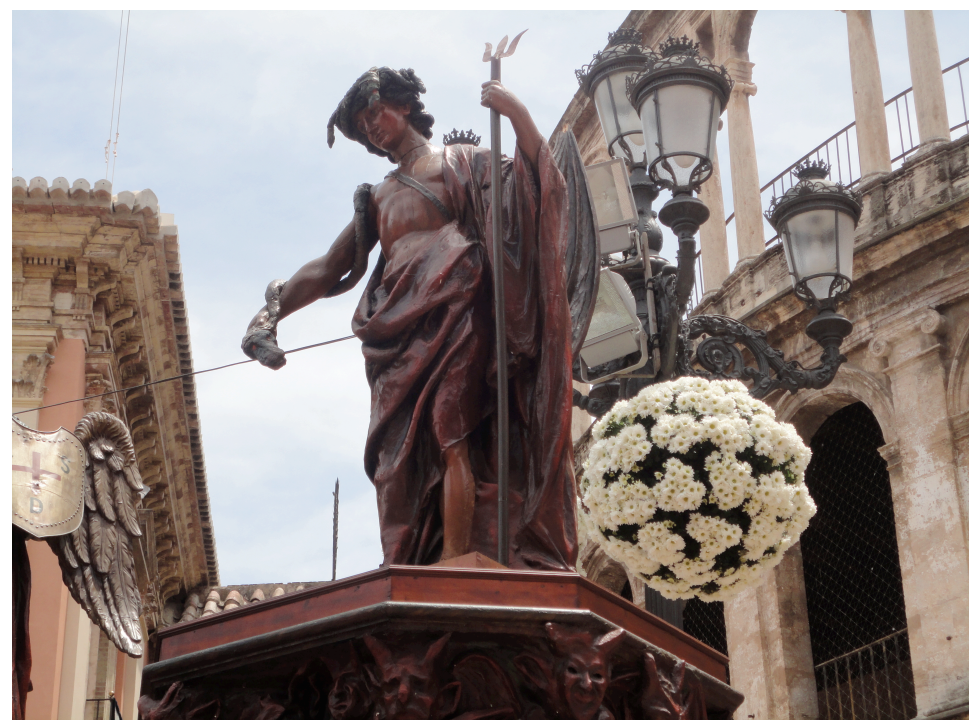

Ilustración 2. Detalle de la Roca del Corpus. Año 2012 (Elaboración propia) 
11. Tribunal de las Aguas de la Vega de Valencia declarado BIC por Decreto 73/2006, de 26 de mayo (DOCV núm. 5269 , de 30 de mayo de 2006), se lleva a cabo el ámbito espacial en la puerta de los apóstoles de la catedral de Valencia, y el ámbito temporal son todos los jueves, a las $12 \mathrm{~h}$.

\section{CONCLUSIONES}

Hemos visto, pues, que la legislación que declara un bien inmaterial como BIC precisa de forma muy clara tanto lo que se considera su ámbito temporal como su ámbito espacial. Es decir, la protección del bien queda plasmado en la delimitación del denominado entorno de protección.

Si bien es cierto que los bienes analizados constituyen fiestas y celebraciones relacionadas con la cultura valenciana, la idiosincrasia de cada uno lo hace único, y de ahí que la delimitación de los espacios u ámbitos sea especialmente importante.

Además de ello, en cada bien se explica las medidas de protección a adoptar, teniendo en cuenta las características propias del bien.

\section{FUENTES REFERENCIALES}

Ramón, Francisca: El patrimonio cultural. Régimen legislativo y su protección. Editorial Tirant lo Blanch, Valencia, 2012, 172 páginas.

Ramón, Francisca: "La declaración de bienes de interés cultural inmaterial y su regulación en la legislación sobre patrimonio cultural valenciano”. En América Latina, globalidad e integración, Ediciones del Orto, Madrid, 2012, páginas 1535-1546.

Ramón, Francisca: "El patrimonio cultural valenciano: estudio de casos y su protección". En Revista jurídica valenciana. Associació de Juristes Valencians (anteriormente Revista Internauta de Práctica Jurídica), enero-junio, 2014, núm. 31 y núm. 3, 22 páginas. [http://www.uv.es/ajv/art_jcos/art_jcos/num31-2/1frapatri.pdf] [31 de marzo de 2015].

Ramón, Francisca: "La protección del «paisaje sonoro»: Los toques manuales de campanas y su declaración como Bien de Interés Cultural”. Culturas. Revista de Gestión Cultural, octubre, 2014, núm. 1, págs. 97-118.

[http://polipapers.upv.es/index.php/cs/article/view/2118] [31 de marzo de 2015]. 